\title{
Synthesis of fluorinated Bis-GMA and its use with other fluorinated monomers to formulate hydrophobic composites
}

T. LI \& R.G. CRAIG School of Dentistry, The University of Michigan, Ann Arbor, MI, U.S.A.

SUMMARY Fluorinated Bis-GMA was synthesized and used with other commercially available fluorinated monomers and diluents to prepare hydrophobic composites. The composites were formulated as onepaste systems and were polymerized using blue light.
Mechanical properties and water-related qualities were determined. Fluorination generally improved the hydrophobicity of the composites, but there was no clear-cut effect on mechanical properties.

\section{Introduction}

The majority of current dental composites are based on a Bis-GMA or urethanedimethacrylate system that are reinforced with up to $80 \%$ by weight of silanted inorganic fillers. These composites have been shown by numerous investigators to have substantially improved physical and mechanical properties compared to unfilled acrylic materials (Vanherle \& Smith, 1985; Craig, 1993). However, even with enamel etching and the use of bonding agents, penetration of oral fluids at the margins and boundaries of composite restorations with tooth structure occurs (Douglas, Chen \& Craig, 1980).

The use of highly hydrophobic composites was shown (Douglas, Craig \& Chen, 1979) to inhibit capillary penetration of water at the tooth-composite interface. They used octafluoropentylmethacrylate with a Bismethacrylate with no hydroxyl groups to formulate their hydrophobic composites, since fluorine-containing polymers have low surface energy and are highly hydrophobic. Fluorinated Bis-GMA was not used since it was not commercially available. Unfortunately, the low molecular weight and large amount of fluorinated monomer needed resulted in a larger than desired polymerization shrinkage.

The objective of this study was to synthesize fluorinated Bis-GMA in order to formulate highly hydrophobic restorative composites, and to evaluate their mechanical and water-related properties.

\section{Materials and methods}

\section{Materials}

Bis-GMA and triethyleneglycoldiacrylate were obtained from Esschem*, and zirconium silicate was supplied by $3 M^{\dagger} .2,2$-Bis (4-hydroxyphenyl)-hexafluoropropane (Bis-phenol F) was purchased from PCR ${ }^{\ddagger}$. Bis-phenol A diacrylate (Bis-DA), Bis-phenol A dimethacrylate (BisDMA), hexafluoro-Bis-phenol A diacrylate (HF Bis-DA), hexafluoro-Bis-phenol A dimethacrylate (HF-Bis-DMA), 1,6-hexamethylene-diol-1,6-diacrylate (HMDA), 1,6hexamethylene-diol-1,6-dimethacrylate (HMDMA), $2,2,3,3,4,4,5,5$-octafluorohexamethylenediol-1,6diacrylate (OFHMDA), and 2,2,3,3,4,4,5,5-octafluorohexamethylenediol-1,6-dimethacrylate (OFHMDMA) were purchased from Monomer Polymer Laboratories ${ }^{\S}$. Camphoroquinone (CQ), glycidyl methacrylate (GMA), tetrabutylammonium chloride $\left(\mathrm{Bu}_{4} \mathrm{~N}^{+} \mathrm{Cl}^{-}\right)$and 2-dimethylaminomethylmethacrylate

* Esschem Co., Essington, PA, U.S.A.

+ 3 M Dental Products, St. Paul, MN, U.S.A.

‡ PCR, Inc., Gainesville, FL, U.S.A.

${ }^{\S}$ Monomer Polymer Laboratories, Windham, NH, U.S.A. 
(DMAMA) were bought from Aldrich*. 3-methacryloxypropyltrimethoxysilane (MAOPTMS) was obtained from Hüls ${ }^{\dagger}$.

\section{Synthesis of Bis-F-GMA}

Bis-phenol $\mathrm{F}(6.72 \mathrm{~g}$ or $20 \mathrm{mmol}), \mathrm{GMA}(5.68 \mathrm{~g}$ or $40 \mathrm{~m} \mathrm{~mol})$, toluene $(20 \mathrm{~g})$ and $\mathrm{Bu}_{4} \mathrm{~N}^{+} \mathrm{Cl}^{-}(0.085 \mathrm{~g})$ were placed in a $250 \mathrm{ml}, 3$-neck flask equipped with a mechanical stirrer, a condenser, a thermometer and a $\mathrm{N}_{2}$ gas inlet. The flask was flushed with $\mathrm{N}_{2}$ and heated slowly to $105^{\circ} \mathrm{C}$ (reflux temperature of toluene) and held at this temperature for $4 \mathrm{~h}$. The solution became light brown in colour during the reaction. The product was precipitated from hexane and was vacuum evaporated at room temperature $\left(24^{\circ} \mathrm{C}\right)$ for 2 days.

The reaction of Bis-phenol F and GMA was as shown in Fig. 1.
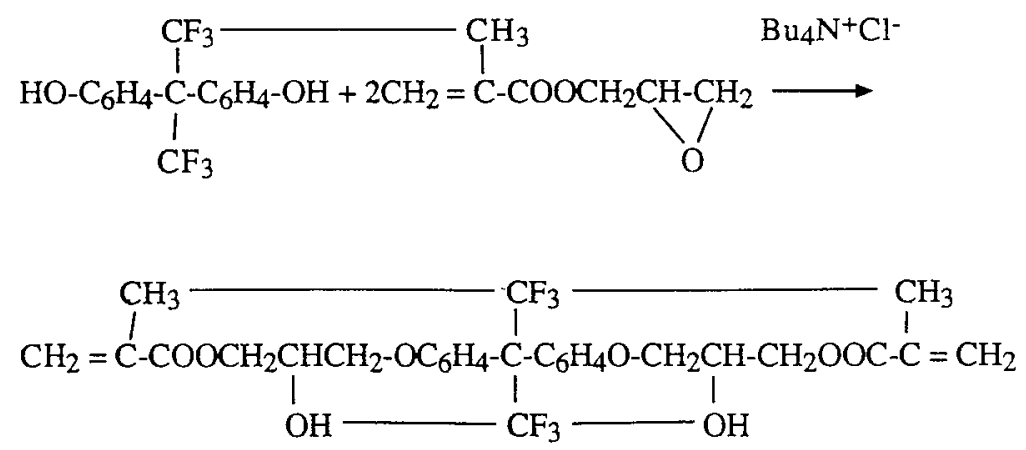

Fig. 1. The reaction of Bis-pherol F and GMA.

Initially, the reaction was carried out in the presence of hydroquinone to prevent polymerization of the oligomer. However, this resulted in a dark coloured product and the hydroquinone residue was difficult to remove. When the reaction was run at the reflux temperature of toluene with no radical trappers present, the reaction proceeded smoothly with no polymerization of the oligomer.

The product showed only one peak by gas chromatography. Mass spectrometer results were as follows: $\mathrm{M}^{+}(10)=620 ; \mathrm{M}^{+}-$GMA $(35)=478 ; \mathrm{M}^{+}-2 \mathrm{GMA}(28)=$ $336 ; \mathrm{M}^{+}-2 \mathrm{GMA}^{-\mathrm{CF}_{3}}(50)=267 ; \mathrm{GMA}^{+}+1(100)=143$. Nuclear magnetic resonance results were: $\mathrm{CH}_{2}=: 5 \cdot 10$, $6 \cdot 20 ; \mathrm{CH}_{3}: 2 \cdot 00, \mathrm{COOCH}_{2}: 4 \cdot 35, \mathrm{CH}: 3 \cdot 65, \mathrm{CH}_{2} \mathrm{OPh}:$ $4 \cdot 05, \mathrm{C}_{6} \mathrm{H}_{4}: 6 \cdot 90,7 \cdot 40$. Infra-red analysis showed: 1640 $\mathrm{cm}^{-1}(\mathrm{C}=\mathrm{C}), 1600 \mathrm{~cm}^{-1}$ (benzene), $1750 \mathrm{~cm}^{-1}(\mathrm{C}=\mathrm{O})$, $3400 \mathrm{~cm}^{-1}(\mathrm{OH})$. Elemental analysis showed $\mathrm{C}=55.68 \%$ (calc. $56 \cdot 12 \%$ ) and $\mathrm{H}=4 \cdot 86 \%$ (calc. $5 \cdot 20 \%$ ).

\footnotetext{
* Aldrich, Milwaukee, WI, U.S.A.

† Hüls America, Inc., Piscataway, NJ, U.S.A.
}

\section{Specimen preparation and testing}

Composites were formulated using oligomers, diluents, initiator system, and silanated ZrSi filler. Silanation of $\mathrm{ZrSi}$ was carried out with MAOPTMS in the presence of ethanol for 90 min using $3 \times$ the monolayer coverage (Mohsen \& Craig, 1995). The oligomer to diluent ratio was $70 / 30$ and the filler/organic ratio was $80 / 20$. CQ/ DMAMA was used as the initiating system with visible light curing (Douglas et al., 1979).

The diametral tensile strength specimens were $0.6 \mathrm{~cm}$ diameter and $0.3 \mathrm{~cm}$ thick. The composites were polymerized in the mould with a clinical light for $90 \mathrm{~s}$ and then in a visible light box for $1 \mathrm{~h}$. The replication number was five.

Specimens for water sorption, solubility and contact angle were made in $2.0 \mathrm{~cm}$ diameter $\times 0.2 \mathrm{~cm}$ thick molds and cured in the same way as the tensile strength specimens. No inorganic filler was used for the contact angle specimens. Tests were conducted according to American Dental Association Specification No. 27 (1989). The replication number was five.

\section{Results}

\section{Composites containing Bis-F-GMA}

Bis-F-GMA did not mix well with the various diluents and it was necessary to use it in combination with BisGMA at a ratio of $1 / 1$. The formulations used of Bis-FGMA and Bis-GMA and for Bis-GMA alone are listed in Table 1 along with their tensile strengths, and water sorptions and solubilities.

Sample 2 with the fluorine-containing oligomer and diluent had the lowest water sorption and solubility but with some sacrifice of tensile strength compared to the composite with Bis-GMA alone.

The contact angles of water for polymer samples without filler, but of the remaining composition similar to samples 1.2 and 3 were $60^{\circ}, 65^{\circ}$ and $50^{\circ}$, respectively, illustrating the effect of the presence of fluorine in both the oligomer and diluent.

\section{Effect of fluorinated diluents on Bis-GMA composites}

The compositions and properties of Bis-GMA-based composites formulated with two fluorinated and two non-fluorinated diluents in the ratio of Bis-GMA to diluent of 70/30 are listed in Table 2. The composites 


\begin{tabular}{|c|c|c|c|}
\hline & \multicolumn{3}{|c|}{ Sample } \\
\hline & 1 & 2 & 3 \\
\hline \multicolumn{4}{|l|}{ Component, g } \\
\hline Bis-F-GMA & 0.693 & 0.693 & 0 \\
\hline Bis-GMA & 0.693 & $0 \cdot 693$ & $1 \cdot 386$ \\
\hline $\mathrm{ZrSi}$ & $8 \cdot 0$ & $8 \cdot 0$ & $8 \cdot 0$ \\
\hline TEGDMA & 0.594 & $0 \cdot 297$ & 0.594 \\
\hline OFHDDA & 0 & $0 \cdot 297$ & 0 \\
\hline $\mathrm{CQ}$ & $0 \cdot 152$ & $0 \cdot 152$ & $0 \cdot 152$ \\
\hline DMAMA & 0.01 & 0.01 & 0.01 \\
\hline \multicolumn{4}{|l|}{ Property } \\
\hline Diametral tensile strength, $\mathrm{kg} / \mathrm{cm}^{2}$ & $369\langle 39\rangle$ & $449(47)$ & $515(47)$ \\
\hline \multicolumn{4}{|l|}{ Water sorption } \\
\hline $\mathrm{mg} / \mathrm{cm}^{2}$ & $1 \cdot 0$ & $0 \cdot 7$ & $1 \cdot 1$ \\
\hline$\%$ & $0.60(0.02)$ & $0.42(0.02)$ & $0.71(0.03)$ \\
\hline \multicolumn{4}{|l|}{ Water solubility } \\
\hline $\mathrm{mg} / \mathrm{cm}^{2}$ & 0.03 & 0.05 & $0 \cdot 10$ \\
\hline$\%$ & $0.02(0.01)$ & $0.03(0.01)$ & $0.06(0.01)$ \\
\hline
\end{tabular}

Table 1. Formulations and properties of Bis-F-GMA and Bis-GMA composites

\begin{tabular}{|c|c|c|c|c|}
\hline & \multicolumn{4}{|c|}{ Sample } \\
\hline & 4 & 5 & 6 & 7 \\
\hline \multicolumn{5}{|l|}{ Component, g } \\
\hline Bis-GMA & $2 \cdot 772$ & $2 \cdot 772$ & $2 \cdot 772$ & $2 \cdot 772$ \\
\hline HMDMA & $1 \cdot 088$ & 0 & 0 & 0 \\
\hline HMDA & 0 & 1.088 & 0 & 0 \\
\hline OFHMDMA & 0 & 0 & 1.088 & 0 \\
\hline OFHMDA & 0 & 0 & 0 & $1 \cdot 088$ \\
\hline $\mathrm{ZrSi}$ & $16 \cdot 0$ & $16 \cdot 0$ & $16 \cdot 0$ & $16 \cdot 0$ \\
\hline $\mathrm{CQ}$ & 0.03 & 0.03 & 0.03 & 0.03 \\
\hline DMAMA & 0.015 & 0.015 & 0.015 & 0.015 \\
\hline \multicolumn{5}{|l|}{ Property } \\
\hline $\begin{array}{l}\text { Diametral tensile strength } \\
\qquad \mathrm{kg} / \mathrm{cm}^{2}\end{array}$ & $432(27)$ & $505(41)$ & $443(33)$ & $526(38)$ \\
\hline \multicolumn{5}{|l|}{ Water sorption } \\
\hline $\mathrm{mg} / \mathrm{cm}^{2}$ & $0 \cdot 83$ & 0.76 & 0.69 & 0.69 \\
\hline$\%$ & $0.53(0.03)$ & $0.50(0.03)$ & $0.43(0.02)$ & $0.43(0.02)$ \\
\hline \multicolumn{5}{|l|}{ Water solubility } \\
\hline $\mathrm{mg} / \mathrm{cm}^{2}$ & $0 \cdot 10$ & 0.09 & 0.07 & 0.07 \\
\hline$\%$ & $0.07(0.02)$ & $0.06(0.02)$ & $0.05(0.02)$ & $0.05(0.02)$ \\
\hline
\end{tabular}

Table 2. Compositions and properties of Bis-GMA composites containing fluorinated and non-fluorinated diluents

formulated with fluorinated diluents had lower water sorption and solubility than those non-fluorinated diluents, however, there was no trend with respect to tensile strength. Composites formulated with OFHMDA diluent had the highest tensile strength followed by those containing HMDA, OFHMDMA and HMDMA. These data suggest that the diacrylate diluents may be superior to the dimethacrylate diluents.

\section{Effect of fluorinated comonomers on Bis-GMA composites}

OF Bis-DA and OF Bis-DMA are solids at room temperature $\left(24^{\circ} \mathrm{C}\right)$ and did not dissolve in diluents such as HMDA and TEGDA. Thus, they were used as comonomers with Bis-GMA (OF Bis-DMA/OF Bis-DA/Bis-GMA of 1 ) 1/2). Their non-fluorinated analogues, Bis-DMA and BisDA were used in the same formulation ratio for 
comparison. The composition and properties of composites formulated with these comonomers are listed in Table 3.

Sample 8 was formulated with non-fluorinated resins and diluents. Sample 9 had fluorinated diluents added, while sample 10 used fluorinated oligomers as part of the resin. Sample 11 was formulated with both fluorinated oligomers and diluents. The water sorption and solubility of samples (9 and 11) containing fluorinated compounds were lower than those without. The contact angle for sample 8 without filler was $65^{\circ}$ compared to $80^{\circ}$ for the formulations containing fluorinated diluent (sample 8) and to $70^{\circ}$ for formulations containing fluorinated oligomers (samples 10 and 11). Samples containing fluorinated diluents (samples 9 and 11) had lower tensile strengths than those containing fluorinated oligomers (sample 10) or no fluorine compounds (sample 8).

\section{Discussion}

In general, incorporating organic compounds containing fluorine into composites increased their hydrophobicity based on water sorption and solubility and water contact angles. However, the use of fluorinated comonomers with Bis-GMA had the most pronounced effect compared to using fluorinated diluents or the synthesized oligomer Bis-F-GMA. Of the formulations containing fluorinated comonomers, composites containing HFHMDMA, HFHMDA, Bis-DMA, Bis-DA and Bis-GMA were the most hydrophobic, having the lowest water sorption and solubility and the highest water contact angle of $80^{\circ}$. However, based on the work of Douglas et al. (1980), a composite would need a contact angle of about $110^{\circ}$ to prevent marginal penetration of fluid between it and tooth structure. Thus, it appears that the oligomer Bis-F-GMA will need to be more highly fluorinated by adding fluorine to the GMA or similar monomer and need to be used with fluorinated comonomers to produce materials with contact angles in the range of $110^{\circ}$.

It also appears that, in general, the use of fluorinated oligomers, diluents or comonomers results in a decrease in diametral tensile strength of $10-30 \%$. Whether this reduction represents a serious problem with fluorinated composites remains to be determined based on other qualities such as abrasion resistance.

Table 3. Composition and properties of Bis-GMA composites containing fluorinated and non-fluorinated comonomers

\begin{tabular}{|c|c|c|c|c|}
\hline & \multicolumn{4}{|c|}{ Sample } \\
\hline & 8 & 9 & 10 & 11 \\
\hline \multicolumn{5}{|l|}{ Component, g } \\
\hline Bis-GMA & $1 \cdot 386$ & $1 \cdot 386$ & $1 \cdot 386$ & $1 \cdot 386$ \\
\hline Bis-DMA & 0.693 & 0.693 & 0 & 0 \\
\hline Bis-DA & 0.693 & 0.693 & 0 & 0 \\
\hline OF Bis-DMA & 0 & 0 & 0.693 & 0.693 \\
\hline OF Bis-DA & 0 & 0 & 0.693 & 0.693 \\
\hline HMDMA & 0.594 & 0 & 0.594 & 0 \\
\hline HMDA & 0.594 & 0 & 0.594 & 0 \\
\hline HFHMDMA & 0 & 0.594 & 0 & 0.594 \\
\hline HFHMDA & 0 & 0.594 & 0 & 0.594 \\
\hline $\mathrm{ZrSi}$ & $16 \cdot 0$ & $16 \cdot 0$ & $16 \cdot 0$ & $16 \cdot 0$ \\
\hline CQ & 0.03 & 0.03 & 0.03 & 0.03 \\
\hline DMAMA & 0.02 & 0.02 & 0.02 & 0.02 \\
\hline \multicolumn{5}{|l|}{ Property } \\
\hline Diametral tensile strength $\mathrm{kg} / \mathrm{cm}^{2}$ & $503(43)$ & $342(37)$ & $456(49)$ & $364(38)$ \\
\hline \multicolumn{5}{|l|}{ Water sorption } \\
\hline $\mathrm{mg} / \mathrm{cm}^{2}$ & 0.66 & 0.52 & $0 \cdot 62$ & 0.59 \\
\hline$\%$ & $0.40(0.04)$ & $0.35(0.03)$ & $0.40(0.03)$ & $0.36(0.02)$ \\
\hline \multicolumn{5}{|l|}{ Water solubility } \\
\hline $\mathrm{mg} / \mathrm{cm}^{2}$ & 0.08 & 0.02 & $0 \cdot 06$ & 0.05 \\
\hline$\%$ & $0.06(0.03)$ & $0.01(0.02)$ & $0.04(0.02)$ & $0.03(0.01)$ \\
\hline Water contact angle, Degrees & $65(2)$ & $80(3)$ & $70(3)$ & $70(2)$ \\
\hline
\end{tabular}




\section{Acknowledgment}

This research was supported by NIDR Specialized Materials Science Research Center Grant P50 DEO9296, from the National Institute of Health, Bethesda, MD.

\section{References}

American Dental Association Council On Dental Materials, Instruments, AND EQUIPMENT (1989) Direct filling resins, Specification No. 27.

Craig, R.G. (1993) Restorative Dental Materials, 9th edn, pp. 135-36, 249-52. Mosby-Year Book, Inc., St. Louis, MO.

Douglas, W.H., Chen, C.J. \& CRaIG, R.G. (1980) Neutron activation analysis of microleakage around a hydrophobic composite. Journal of Dental Research, 59, 1507.

Douglas, W.H., Craig, R.G. \& Chen, C.J. (1979) A new composite restorative based on a hydrophobic matrix. Journal of Dental Research, 58, 1981.

Mohsen, N.M. \& Craig, R.G. (1995) Effect of silanation of fillers on their dispersability by monomer systems. Journal of Oral Rehabilitation, 22, 183.

VAnherle, G. \& S Sith, D.C. (1985) Posterior Composite Resin Dental Restorative Materials, pp. 199-211. Peter Szulc Publishing Co., the Netherlands.

Correspondence: Dr Robert G. Craig, Department of Biologic and Materials Science, School of Dentistry, University of Michigan, Ann Arbor, Michigan 48109-1078, U.S.A. 
This document is a scanned copy of a printed document. No warranty is given about the accuracy of the copy. Users should refer to the original published version of the material. 